\title{
The authority of science and the legitimacy of international organisations: OECD, UNESCO and World Bank in global education governance
}

\section{Mike Zapp}

To cite this article: Mike Zapp (2020): The authority of science and the legitimacy of international organisations: OECD, UNESCO and World Bank in global education governance, Compare: A Journal of Comparative and International Education, DOI: 10.1080/03057925.2019.1702503

To link to this article: https://doi.org/10.1080/03057925.2019.1702503

View supplementary material $₫$

曲 Published online: 07 Jan 2020.

Submit your article to this journal $₫$

Q View related articles $\asymp$

View Crossmark data $₫$ 


\title{
The authority of science and the legitimacy of international organisations: OECD, UNESCO and World Bank in global education governance
}

\author{
Mike Zappa ${ }^{\mathrm{a} b \mathrm{~b}}$
}

${ }^{a}$ Institute of Education and Society, Université de Luxembourg, Luxembourg, Europe; ${ }^{b}$ American Institute of Contemporary German Studies, Johns Hopkins University, Baltimore, MD, USA

\begin{abstract}
International organisations' (IOs) legitimacy in global educational governance is commonly seen as a function of their regulative or normative power. By contrast, this paper stresses the increasing importance of scientific research and policy-relevant knowledge and its strategic production, dissemination and transfer by IOs. The article examines knowledge work at OECD, UNESCO and World Bank based on novel data from publication analyses, archival work and a number of interviews. Drawing on sociological institutionalism and constructivist international relations scholarship, this study is interested in the rationales, resources and capacities for knowledge production, the strategies of dissemination and transfer as well as the implications of science production for IOs' position and relevance in global governance. Findings emphasise the authority of science as the primary source of legitimacy - and even survival - in an increasingly crowded and competitive field of global education governance.
\end{abstract}

\section{KEYWORDS}

International organisations; global education governance; science and research; organisational legitimacy; epistemic governance

\section{Introduction}

International organisations (IOs), and particularly intergovernmental organisations (IGOs), have been extensively studied in global education governance. Their influence is commonly understood as either operating through hard governance, i.e. mainly financial and regulatory instruments, or soft governance, i.e. mainly agenda-setting and persuasive tactics.

By contrast, this article advances two novel arguments in the study of IOs and their role in global education governance. First, this work posits that IOs' legitimacy increasingly depends on their reliance on, broadly speaking, scientific knowledge in global education policy, making evidence the primary basis of decision-making. The concept of legitimacy used in this work differs from the dominant understanding in international relations where it is usually considered a function of democratic control (see Zürn 2018 for a review). Instead, I draw on concepts of legitimacy from organisational theory where legitimacy describes multiple dimensions of acceptability, reputation and status-building resting on multiple sources fed by organisational environments including rules (i.e. regulative logic), 
norms (i.e. normative logic) and knowledge (i.e. cultural-cognitive logic) (Edwards et al. 2018; Suchman 1995). Relating to this latter cultural-cognitive source of legitimacy, IOs, particularly IGOs, have become veritable science powerhouses in the past two decades. With a strikingly expansive research output in both in-house publications and scientific journal publications, many IOs are now among the biggest research producers worldwide, even ahead of the most prominent universities, particularly in the education sector (Zapp 2017). In the context of evidence-based policymaking, such productivity provides them with a qualitatively novel position in global education.

Second, IOs, aware of the authority of science in global policy discourses, have started to employ science as a strategic tool in advancing their own and influencing countries' agendas. Here, the strategic production, dissemination and transfer of scientific and policy-relevant knowledge gives those IOs that favour 'exploration' (e.g. experimentation, discovery, innovation) a comparative advantage vis-à-vis others that remain in a state of 'exploitation' (e.g. routines, refinement, implementation) (March 1991). Scientific exploration and its efficient dissemination and transfer, thus, become the basis of legitimacy and provide a competitive edge in global education governance.

Since the Education for All summit in Jomtien, Thailand, in 1990, education has become a complex global organisational field bringing together bilateral and multilateral, inter-governmental and non-governmental as well as global and regional actors (Zapp and Dahmen 2017). In this field, the role of scientific knowledge has been identified as crucial in explaining legitimacy and dominance (Chabbott 2003). Some IOs are more pro-active in using their resources in order to produce and diffuse scientific knowledge, finally shaping the agenda in global education.

This article analyses the complex processes of production, dissemination and transfer as seen from inside IOs as such an internal perspective has been out of scope in previous research.

This paper presents novel data on IOs' scientific output, and the rationales and implications of such 'knowledge shifts' gleaned from archives and interviews with IO staff. The focus is on the three most important IGOs in global education: The Organisation for Economic Cooperation and Development (OECD), the United Nations Education, Scientific and Cultural Organisation (UNESCO) and the World Bank (WB). The importance of these three organisations in global education governance has been repeatedly highlighted, yet their expansive research portfolio and use of scientific knowledge have attracted only little attention thus far (Moutsios 2009; Zapp 2017a). Findings show that all three IOs acknowledge the growing importance of science in global governance, yet possess and mobilise varying material, personnel and cognitive resources to effectively produce, disseminate and transfer scientific knowledge in general and research knowledge in particular. While the WB has long sought to become the 'Knowledge Bank' in education (and beyond), the OECD has only recently and successfully intensified such efforts. Finally, the UNESCO, lacking necessary resources, is alarmed to see its voice increasingly muted in a growing global discourse on evidence-based education policymaking, yet has found a viable tool in its recent reporting initiatives. Interviewees from all three IOs see scientific knowledge as the most powerful source in advancing their agenda and in countering political resistance from member states. They also stress features such as originality, quality and 
transferability as crucial criteria for success, traditionally only considered in the context of academic organisations.

The paper concludes by defining research knowledge as the primary source of organisational legitimacy and proposes multiple avenues for further research with a focus on the role of scientific research in global education policymaking.

\section{Prevailing views on international organisations in global educational governance}

Research on global educational governance has vastly grown in the last twenty years. As for other policy areas, international organisations (IOs) have come to be seen as crucial actors in these new policy-making networks. Their specific role is usually described in the classic distinction between hard or coercive and soft or normative influence mechanisms (Nye 1990). It is worth clarifying the main arguments in the context of education.

Traditionally, research on global social and education policy mainly focuses on 'hard power' instruments. With IOs often conceptualised as a tool of powerful states, these are seen as imposing their ideas on IOs, which then impose these ideas on weaker states. In a rational and hard-boiled world where powerful actors compete among each other for dominance, regulation and coercion are the main foci of interest. Classic examples are WB and IMF conditionalities or lending in general (Jones 2007; Moutsios 2009). Here, financial and technical leverage might prompt states to act as expected. WTO/GATS might be another example of (controversial) regulation in education (Scherrer 2007).

By contrast, soft instruments have received growing interest only recently. 'Soft' in this sense refers to normative mechanisms. In these softer versions, IOs become 'knowledge brokers' (Jakobi 2009; Niemann and Martens 2018) or 'norm entrepreneurs' (Barnett and Finnemore 2004), often with a particular focus on IOs' role in diffusing large-scale assessment in the 'age of measurement' (Biesta 2009; also, Meyer and Benavot 2013). Zapp (2018) counted N = 44 IOinitiated international assessments with a growing number of countries worldwide participating. Kallo $(2006,282)$ analyses OECD soft governance in terms of 'strategic consulting, peer pressure, public studies and direct and indirect agendasetting'. Jakobi (2009) analyses the activities from UNESCO, EU, OECD and WB in the global diffusion of lifelong learning. While she finds funding, technical assistance and coordination at the coercive side, dissemination and standardsetting fall into the normative category.

As difficult as it may be to empirically examine the differential impact of these types of governance, it seems that IOs are well-placed to influence other actors (e.g. nation-states, other IGOs and INGOs) by 'making them do', by forcing, tricking, paying, talking, persuading, pleading and socialising. But this influence is not always exerted in a direct way and is not always successful. Both the foci on coercive instruments and soft norms obscure the fact that more is at work. In the following section, I argue that IOs not only exert pressure and diffuse norms, they increasingly provide the most authoritative and policy-relevant knowledge in education. This knowledge, then, 'codified' into applicable recommendations 
serves as the basis of global discourses, and is often requested and used by national policymakers as a blueprint for domestic reform.

\section{International organisations and global education governance through scientific knowledge}

International organisations have become veritable powerhouses of scientific research. Zapp (2017), based on a sample of $\mathrm{N}=604$ intergovernmental organisations from a wide range of policy sectors, finds that scientific articles published by IGOs dramatically increased in the past two decades. These IOs published more since the early 2000s than in the 40 years before. While publication growth rates are astonishing for a wide range of sectors (e.g. environment, health, economic development), education is among the most important research areas.

Such a 'knowledge turn' has not remained unnoticed in the relevant literature. Scholarship with a fresh perspective on global educational governance has begun to look at the emerging knowledge work done at the IO level. These important studies are situated at the soft, i.e. cognitive, end of the array of governance mechanisms.

Among the specific instruments under scrutiny in these contributions are the (sometimes biased) generation, deployment and teaching of research-based knowledge (Broad 2007; Dethier 2007; Rao and Woolcock 2007), the classification of educational systems around the world through educational indicators (Steiner-Khamsi 2009) and the use of quantitative methods as a technology of governance in general (Klees and Edwards 2014). These contributions address the dilemmas of designing learning metrics and they concern the general effects of a growing quantification of education policy (Gorur 2016). As in many fields, quantified reporting has become the basis of an attempt to institutionalise evidence-based policy-making in education. Obviously, such quest for 'evidence' is rooted in a specific kind of educational research. This research might be referred to as quantitative, empirical-analytical, applicability-oriented, problem-based, multidisciplinary, and some might say, more medicalised (Tröhler 2015).

This burgeoning body of work is valuable as it pays attention to a novel science-based mode of global governance that has emerged in the more recent period. What remains out of scope in these studies are, however, the internal perceptions and processes underlying such 'academic drift' at the IO level as well as the wider implications for interIO and state-IO relations. The following section introduces a focus on the authority of scientific knowledge as a source of legitimacy in global educational governance.

\section{The authority of science and organisational legitimacy}

International organisations have only recently been discovered as autonomous organisations that position themselves in organisational fields and that seek legitimacy for their activities (Ellis 2010). Long understood as instruments of powerful states or bureaucracies, their internal processes and inter-organisational relationships were largely obscured by the belief they serve as functional (or sometimes dysfunctional) tools or arenas in multilateral regimes (Mundy 2007; Parreira do Amaral 2010).

Instead, this paper argues that IOs, as any organisation, seek legitimacy as a key good in organisational performance and survival (Tallberg and Zürn 2019). Institutional 
theory suggests that organisational performance and 'relevance' depends not only on material resources and technical information, but on the organisation's perceived legitimacy. In a seminal contribution, Suchman $(1995,574)$ defines organisational legitimacy as the 'generalized perception or assumption that the actions of an entity are desirable, proper, or appropriate within a social system'.

However, Suchman's generalised perception needs to be specified in the context of global education policy as this field is socio-political in nature, involves multiple stakeholders (e.g. inter-, non-, and governmental actors) and represents a highly normative discourse. In line with Edwards et al. (2018), legitimacy can be specified as consisting of socio-political acceptability, reputation and status. Sociopolitical acceptability can be achieved by an IO by (a) adapting to its context, (b) responding to changing expectations, and (c) invoking or affiliating itself with symbols (or other organisations) that possess legitimacy. Reputation reflects the prestige accorded to the organisation based on past performance and quality of work vis-à-vis multiple stakeholders. Finally, status is defined as the 'prominence of an actor's relative position within a population of actors' (Wejnert 2002). These components are inter-related and mutually reinforcing. For example, an increase in sociopolitical acceptability through a successful change in the organisational agenda, can increase reputation in light of a growing number of supporting stakeholders and, over time, increase an organisation's status. It is important to note that while sociopolitical acceptability can be actively pursued by the organisation, reputation and status is something that is conferred to organisational by the organisational environment (Suchman 1995). In the context of IOs, the environment consists of other IOs and, importantly, nation-states as IOs' members, funders and 'clients'. Thus, IOs depend on countries' approval and support to continue their operations. In securing ongoing relevance, it is thus important for IOs to provide legitimacy to themselves and their recommendations.

Following DiMaggio and Powell (1983) and Scott (2013), there are three sources of legitimacy, either by virtue of being legally-sanctioned (regulative), morally-governed (normative), or culturally-supported (cognitive). This three-fold distinction loosely translates into the hard-soft governance continuum found in IR scholarship, with regulative legitimacy operating through hard governance and normative and cognitive processes reflecting soft governance.

In line with constructivist international relations and sociological scholarship in a neoinstitutional tradition where 'soft' factors such as ideas, norms and knowledge are given analytical primacy (Barnett and Finnemore 2004; Wiseman, Astiz, and Baker 2014), this paper emphasises the cultural-cognitive dimension as a source of legitimacy. This source is warranted by scientific knowledge in general and policy-relevant expertise in particular reflecting two wider processes. First, it reflects recent macro trends of scientific expansion and rationalised planning in general and evidence-based policymaking in particular (Drori et al. 2003; Normand 2016). Driven by a highly utilitarian science for development policy model, universities proliferate as do enrolment, science associations, government science infrastructure and investments, scientific output and international research collaborations (see Zapp 2017b for a review). Related, the notion of evidence-based policy-making has spread quickly since the late 1990s. Often imported into education from social policy and health sectors, it has led to new organisational infrastructure and new networks in research and policymaking (Normand 2016) and is 
certainly the core of the 'new orthodoxy' (Oancea 2007) in educational research in various countries but also the European Union (see Zapp, Marques, and Powell 2018 for a review).

Second, it reflects the observation that organisational success is associated with organisations' inclination towards exploration and research. Following March's (1991) classical distinction of exploration versus exploitation, those organisations that take the risk to invest in discovering new knowledge instead of exploiting old certainties are likely to be more adaptive and successful in the long run. Successful knowledge exploration puts these organisations in a comparative advantage vis-à-vis other organisations in the field. These pioneers become templates and role models imitated and emulated by other organisations (DiMaggio and Powell 1983).

This paper argues that IOs increasingly adapt to the changing demands of stakeholders to provide evidence-based policy-relevant knowledge (socio-political acceptability) and use the authority of science to increase their reputation in global governance, especially when competing with other organisations (status) They do so by actively (sometimes proactively) generating and disseminating new scientific knowledge as well as translating this knowledge into actionable policy recommendations and universal standards.

\section{Methodology}

\section{Case selection}

Cases have been selected based on the importance of OECD, UNESCO and WB in the global education discourse. These three IOs have been repeatedly found to be the most relevant organisations in educational policymaking worldwide (see Zapp and Dahmen 2017 for a review).

Founded after World War II in the spirit of scientific humanism and cosmopolitanism, UNESCO combines educational goals with a mission of peace and progress. UNESCO has always been a political actor taking a stance in geopolitical debates and, as a consequence, facing withdrawals from important members such as the UK and the US (Pavone 2007). However, UNESCO was successful in drumming up continuous support for its Education for All initiative since 1990 and has recently taken the lead in global educational reporting through its Global Education Monitoring Report (GEMR), its flagship publication (Edwards et al. 2018).

Contrary to the conventional wisdom, the OECD, founded in 1961, was never absent in the international educational discourse as its work on recurrent education, for example, in the late 1960s and throughout the 1970s shows (Bürgi 2016). In the late 1990s, with the controversial Programme for International Student Assessment (PISA), OECD became more prominent in education. Only in 2002, however, was education given a directorate in its own right. Since then, the OECD, through its Centre for Educational Research and Innovation, has expanded its expertise in large-scale assessment at all levels from primary to adult education. Although limited to only 36 official members, the OECD's reach in education has become global with an increasing number of non-OECD countries joining PISA and the OECD currently piloting PISA for Development, which also covers many low- and middle-income countries (Zapp 2018, 2019). 
Third, the WB, founded in 1944 to assist in post-war reconstruction, has gradually evolved from a global financial facilitator into an important agency involved in funding, advising and designing educational policies worldwide. While its early work in education prioritised on resources for infrastructure and manpower training, its focus shifted, along with the general development discourse, to basic education and early childhood education in the 1970s and 1980s (Chabbott 2003; Jones 2007). Today, the WB is, by far, the largest funding and project-implementing institution in education in the world covering all educational sectors from early childhood care and education to tertiary education and lifelong learning (Zapp 2017a).

The role of UNESCO, OECD and WB as scientific producers has been documented in previous research (Zapp 2017). Indeed, for education these three organisations account for the vast majority of all academic publications on education published by a large sample of 181 IGOs. While the average IGO publishes around 15 publications on education per year, these three key actors have increased their output to between 220 and more than 1,000 publications in the more recent period.

\section{Data}

Analysis is based on two kinds of data. First, I conducted a series of semi-structured expert interviews with senior research staff. For each organisation, four experts were interviewed (60-90 $\mathrm{min})$. When possible, I chose interviewees whose role was significant throughout a long period. Interviewees' careers span between 6 and 21 years at their organisation. In addition, many of these actors have had multiple functions during their career. They were, for example, active as researcher, advisory board member, project leader, consultant and department head. This is to ensure that analyses encompass several perspectives. All interviewees, except one ${ }^{1}$, were at the time of writing actively involved in the research divisions of the respective organisations. Their disciplinary background was diverse including education, statistics, economics, psychology, political science and anthropology. To assure anonymity, interviewees are coded by letters and Roman numbers, i.e. $\mathrm{U}$ for UNESCO, $\mathrm{O}$ for OECD and $\mathrm{W}$ for World Bank.

Second, for the WB, I also rely on hitherto unanalysed material from the organisation's archives in its Washington, DC, headquarter. ${ }^{2}$ I collected key transcripts from educational sector board meetings as well as staff output that document the internal climate since the late 1990s: memoranda and research notes, staff reports, emails and personal communiqués, minutes of meetings between education staff and between education staff and board. Archival notes are abbreviated as AN with related Roman numbers.

\section{Analysis}

For content analysis, I applied the main grounded theory tools of constant comparison, (open, axial, selective) coding, memo writing and integration of categories supported by the software MAXQDA (Corbin and Strauss 2008). Grounded theory was used as it provides a rich toolbox of analytical techniques that can be adapted to the requirements of the research process. It is one of the most prominent approaches to qualitative data 
analysis and has, since its beginnings, frequently been used to analyse interviews (Bryant and Charmaz 2007). The main objective of grounded theory is to initiate an ongoing iteration between data collection and analysis on the one hand and reflection and theorybuilding on the other.

Such an iterative process complemented the research process which rested on three broad key questions that guided the interviews and subsequent analysis. These revolve around knowledge production as well as knowledge dissemination and knowledge transfer, which can be seen as successive steps in a knowledge cycle and which were identified as a useful heuristic in previous research on IOs' scientific work (Zapp 2017a). In line with the grounded theory methodology, these core categories were, then, substantially bolstered with lower-level sub-categories that helped to further integrate data across the three cases and to add more particular analytical thrust to each individual case. For example, while these key three questions were crucial in initiating the conversation, additional questions centred on the causes, contexts, conditions and consequences of production, dissemination and transfer of scientific knowledge. These sub-categories stem in part from the general grounded theory approach (Corbin and Strauss 2008), but were also generated inductively during the analysis. Whenever these sub-categories provided additional analytical thrust, there were used to achieve greater data saturation. Appendix A provides a selected account of the analytical framework.

\section{Findings}

The presentation of findings is organised around the three core categories which revolve around questions of scientific knowledge production, scientific knowledge dissemination as well as transfer.

\section{Knowledge production: international organisations as 'reasonable empires of what works'}

The 'knowledge turn', best documented by the impressive increase in scientific publications in the past two decades (Zapp 2017), begs for an explanation. Interviewees suggest four (inter-related) reasons for this rather sudden shift. A first, pragmatic, reason is career planning. Researchers and employees in general from across organisational units (e.g. operations and field work versus planning and evaluation) often work on fixed-term contracts, in many cases ranging from two to five years. Recruited from academia or research institutes, some of these employees often consider returning to researchintensive employment outside of the IO sector after their contract ends (O1). Maintaining an active and visible research portfolio is a viable strategy to signal an ongoing research agenda to future employers.

Another explanation for the massive increase in science output is that IOs can increasingly recruit from a large pool of candidates trained at schools of international education and development studies and equipped with strong analytical skills (W4; W2). Although in many operational fields other (diplomatic, management, language) skills still play a vital role (O3), IOs are getting 'scientised' by a new generation of university graduates. Some even do their $\mathrm{PhD}$ at the organisation while collaborating with 
universities. Research training has also expanded at IOs themselves, further improving analytical skills on the job (W4).

A third reason stressed by many interviewees is the increasing availability of data. Most interviewees confirm the increase in data, its availability and accessibility. Some call it the most important 'revolution' since the 1980s (W1) and stress the transparency of methodologies at IOs which helps other researchers to easily reproduce the studies $(\mathrm{O} 2$, O1). The role of large-scale achievement testing such as PISA but also surveys like the WB's Skills Towards Employment Productivity are particularly important and emphasised by multiple interviewees.

Together with increasing data coverage, a fourth and very important explanation for the knowledge turn becomes salient. All interviewees agree (albeit to some's dislike) that the authority of scientific evidence is something IOs cannot leave aside in the global discourse on education reform.

Evidence, in most cases, quantitative, indicator-based evidence, is requested by various stakeholders including NGOs, governments, schools, parents and funding agencies:

"Most policymakers nowadays want evidence and numbers. Without data, it's very hard to make a case, or a point. I don't think we do anything but evidence-based policymaking. That's our focus. Everything that we advise governments on, anything that we work on, as much as possible." (W2)

"For us to put forward some positions of advocacy in the absence of any kind of evidence would be highly problematic. Evidence is certainly the name of the game." (U1)

This contrasts with the older era where data was scant and evidence not necessarily the basis for decision-making.

"There might be a certain class of politicians harking back to the good old days when they didn't have to support anything with evidence, but I think is becoming increasingly rare." (O3)

"When I started my career [late 1970s] there was virtually no data out there to base your judgement on. So, they [client countries] look at the Bank as a reasonable empire of what works and what doesn't and how money should be spent. The analyses they [WB researchers] produce are largely helpful and quoted in the New York Times and the Economist and academia." (W1)

The role of evidence is important in multiple ways: it serves as basis for bolstering recommendations to countries, helps decide IOs' on their agenda, influences the internal allocation of funds and, in the case of the $\mathrm{WB}$, determines lending priorities. In general, it establishes a common language among sectors and operational units, IOs and stakeholders.

Internally, IOs resemble traditional research institutes: they have internal peer reviews across units, they routinely discuss their findings in internal meetings before moving on in their research design ( $\mathrm{AN} \# 12-16)$ and consult external experts in their projects (O1, W3).

Interviewees stress the authority of evidence in highly politicised negotiations. When country officials seek symbolic reforms (e.g. equipping every student with a computer) (W4; AN \# 8), criticise reports for the unfair treatment of their country (U2) or request a particular research to be conducted in the future $(\mathrm{O} 1)$, researchers point to the state of the art to defend their positions. 
That does not mean evidence replaces politics as one interviewee repeatedly stresses (O2), yet it creates a space for negotiations although this space is not uncontested (see below).

All interviewees agree on the strong premium on scientifically-buttressed knowledge generation, yet they have different views of how well their organisation is equipped to meet this new paradigm. Two main resources are highlighted: money and skilled staff and, importantly, originality.

Financial resources are an obvious condition to conduct research. All three IOs are primarily dependent on the support from their country members, yet some have started to seek other funding partners including smaller country consortia and sometimes even individual countries, other IOs and nongovernmental organisations and, more recently, the private sector like philanthropic and corporate funds and companies.

IOs differ in how their financing mode plays out for their research capacity. The wealthiest $\mathrm{IO}$, the $\mathrm{WB}$, has been successful in diversifying their funding portfolio with an increasing number of partners from the private sector directly funding research (W4). The OECD, as a specialised think tank, is explicitly tasked by country members to conduct research on particular subjects although country priorities can be mediated by OECD expertise. Research, here, is 'customer-driven' and suffers less from the volatility that comes with political mandates (O1). UNESCO, by contrast, admits and is seen by other IOs, to be highly underfunded (U1, U2, W3, W1). These resource problems can be detrimental. Consequences range from limited access to journals and digital libraries (e.g. jstor) to the lack of employed researchers with particular expertise (and the increasing out-contracting of research tasks) and, most importantly, the lack of funds to gather primary data through novel surveys and studies (U2). For UNESCO's GEMR, its most important educational outlet, it was important to secure funding independent from the wider UNESCO architecture. Consequentially, the GEMR team is more flexible to drum up support from unusual sources as is the case with GEMR-associated Youth Report funded by the MasterCard Foundation (U1; U3).

While all interviewees agree that generating new data and theory is a costly enterprise, they also stress that it is equally important (and risky) to explore unchartered knowledge territories. Notions reminiscent of academia like 'originality', 'innovation' and 'pioneering research' appear in most interviews.

OECD researchers, for instance, want to 'be at the research front of measurements per se' (O1), while feeling 'a lot of internal pressure to try something new.' PISA's recent Innovative Domain is one response to such pressure. Now, every PISA cycle includes a new domain (e.g. problem-solving or financial literacy) in order to signal innovation. WB interviewees also stress that there has always been 'more room for innovation'. Low bureaucratic hurdles, inspiring leaders, the unique blend of technical expertise and highprofile research expertise are mentioned as key in WB success (W2). Large-scale surveys are constantly updated and used as a playing ground to experiment with new indicators and samples: 'We are learning as we go - it's just the beginning' (W2).

UNESCO, given its smaller research capacity, is aware of the fact that if they do not produce original research they might lose out to others in the field (U2). Research positions that were key in the past and that had not been filled due to budget constraints are seen as a massive loss of voice and relevance in the field. Nonetheless, the goal for UNESCO, and 
the GEMR in particular, is to produce 'cutting edge research' (U1) and to provide a novel view on data through extensive technical reports and background material.

In many cases, IOs do research based on the 'message from the cutting-edge research out there and from countries that are interested in having support' (W3). Yet, the novel area of social and emotional skills is a particularly instructive example that demonstrates that IOs can themselves advance a burgeoning agenda. Developing a research agenda is, therefore, motivated by external (previous research and country demands) and internal factors.

It also shows the advantage of IOs as platforms where interdisciplinarity is more easily established around particular problems as opposed to traditional academia where disciplinary boundaries persist:

"We are now getting into social and emotional skills. And these are completely new. They haven't been done before with that scope, scale and approach. We have neurologists, psychologists and all kinds of researchers, to really try to tease out how to set up the items so they really do measure what they want to measure. These emotional and social things are difficult to grasp and the OECD does work on capturing these for the first time." (O1)

Developing a novel research domain is a daunting task. It means bringing academia, policymaking and IOs together. It involves extensive systematic reviews, facilitating collaboration between sometimes disparate scientific communities, bridging cleavages between methodological camps and also between these three and other IOs (W3). Strong reputational standing does, however, facilitate such collaborative enterprises and when IOs invite experts, 'they usually come because we have reputation' (O2)

Finally, advancing innovative research also involves risks:

"Sometimes we are also ahead of academia although this is quite risky since we are prominent, all eyes are on us. But, for example, the next innovative domain will be global competences for 2017. That is an entirely new cognitive domain. We will come up with new indicators about how competent students are living in an increasingly interconnected world. That will be an agenda-setting construct." (O2)

Producing knowledge is only the first step in a 'knowledge cycle'. Findings need to be disseminated and the following section shows what strategies are used in this process.

\section{Knowledge dissemination: 'conferences, reports, papers, radio, TV, tweets ...'}

The previous section has shown that IOs are aware of the importance of research in order to stay 'relevant' in the international education policy discourse. The role of resources and originality was seen as crucial in gaining a competitive edge in an increasingly crowded policy field. Resources are equally important when it comes to the dissemination of produced knowledge to, primarily, policymakers, but also the media and practitioners. All interviewees agree on the critical importance of such diffusion, yet pursue different strategies.

The WB, possessing the largest resources, for example, uses films (e.g. the WB Africa Film Series with the film The First Grader dealing with primary education), radio (e.g. the WB Radio Instruction to Strengthen Education in Zanzibar), and social media (e.g. the World Development Report App or the WB Education Blog, Twitter, Flipboard etc.). In 
2015 alone, the WB sponsored conferences and other events such as talks, seminars, lectures and workshops on 99 occasions on a wide array of topics ranging from agriculture to urban planning and education. A typical year has up to nine regional conferences in such places as Delhi, Cairo, Santiago de Chile, Ouagadougou, Buenos Aires, Saint Lucia, Issyk-Kul, Almaty and Samarkand all dealing with latest educational issues and accompanied by a wide array of capacity development workshops. Many archival notes (\#13-16) also report on WB researchers presenting their findings on scientific conferences, the (sometimes very critical) feedback from academia on WB research (and WB work in general) and how to take such critical feedback into account in future work.

All organisations have made strategic decisions to facilitate dissemination and it has become an important task to widen the audience:

"From the OECD perspective, I think there has been a real shift to work on dissemination, impact, engage different audiences, not just researchers, and policymakers but parents and the media, students, a much broader set of constituents. The intention is very deliberate, to try and open up the discussion and get more people engaged." (O3)

Such diversification of output is being discussed everywhere. More targeted and tailored outputs (on specific groups like gender or out-of-school children, for example), and distilled products ranging from Campbell and Cochrane-style reviews (U2) to cartoons and animations (U1). Researchers stress that they defend low firewalls, free downloads, accessibility in search engines but also in language and intelligibility. They would like to see their products diffusing not only to policymakers but into the wider community including other IOs, the media, graduate schools, colleges, schools, and parents. Such ambition partly stems from pressure from inside their organisations, but also advisory boards, the donor community and individual funding organisations (W4). In general, their concern is also that they owe 'to our clients and to the people in these countries to bring the best knowledge to bear' (W3).

However strong the desire to reach out with succinct knowledge, IO researchers are also aware of the challenges involved:

"The PISA reports are 2000 pages, when you put all the volumes together. So, by definition when you produce something for parents, you're producing something in a much more condensed format. But in order to do that, you have to produce very slimmed down reports." (O3)

"We spend a year and half on the Global Education Monitoring Report, which has now more than 400 pages and 60 pages of scientific references and it is still not nearly as nuanced as I would like it to be, and the communication office is trying to put that in a tweet." (U2)

While dissemination is a general diffusion process, the final section takes a closer look at the more specific interaction with policymakers and the targeted transfer of policyrelevant knowledge.

\section{Knowledge transfer: 'we bring three worlds together'}

The dissemination of findings and, more generally, information is crucial in guaranteeing organisational visibility and keeping a hat in the ring. However, beyond broad 
dissemination across a general audience including media, parents and experts, the most important target for knowledge diffusion are policymakers.

Some IOs have a designated department for such transfer work as in the case of the OECD, the Policy Advice and Implementation Unit. In general, one OECD researcher describes IOs' job as:

"International organisations take on the role of picking up research and making it more applicable to the real world. We bring three worlds together: the research and the policy and implementation level as well as the level of politics. That's what researchers usually don't do. International organisations translate these things with educational policy in mind and to how to apply it best." (O1)

UNESCO, too, realises that no matter how many different summaries and country briefs, regional and gender-specific reports and datasets are produced, 'what policymakers want is support' (U2).

Yet, the interstitial position of IOs between science and policymaking is not necessarily a comfortable position as many researchers stress. Finding the right language, space and timeframe to exchange findings with policymakers can be a daunting task as 'policy operates on a very different timeline than research staff. Being able to create those platforms and links is actually more complex than just getting people to sit down together' (O3).

Ironically, a consequence of the growing use of evidence in the policy-IO relationship is that policymakers' thirst for data has turned into data fatigue.

"There is all this push for more information and more data, but that has overwhelmed policymakers, teachers and principals, they were trying to get all this in to improve their education or to improve their teaching. And they are overwhelmed because they are not trained in it, it's piecemeal, it's not designed for that purpose." (W1)

That does not prevent countries from asking for more data and again IOs step in as knowledge navigators:

"There is a lot of data for sure. And no one individual can digest that data, so we help countries to understand and interpret that data. But countries often want even more questions in our questionnaires." (O2)

Finally, another consequence from the growing reliance and science and its proximity to policy-making as well as its dependence on funding is the concern that socioscientific knowledge suffers from biases and ambiguity. Research risks becoming a Procrustean bed where findings are stretched and cropped to provide a fit for everybody's purpose. First, it serves researchers' purpose in the allocation of funding vis-à-vis directors and research groups from other fields:

"When I was doing research at the Bank, I was doing research to get the numbers to promote schools. You have to understand I am in competition with other sectors, its business, I am in competition with agriculture and industry and hydroelectric power. Everyone wants more head start. So, research done by the implementing agencies is biased from the beginning." (W1)

Further, whenever researchers' paradigms and worldviews clash, the subjectivity of social sciences becomes apparent: 
"We have evidence to back it up and someone else has their evidence to back it up ... so finding out what really works in education is very difficult, which might be different in the health field." (U2)

"I can predict the result of a research project only by knowing nothing more than the author's name. Let's say on school choice, you can line up 25 articles and I'll tell you what author finds private better and which one prefers public schools." (W1)

In general, researchers are aware and honest about underlying methodological paradigms and political agendas reigning in particular organisations, organisational sub-units and research teams. In this sense, IO research in education is also an arena for battles over ideas and ideologies, namely a public service idea in WB and OECD versus a public good and human rights idea at UNESCO. At the same time, interviewees acknowledge that these boundaries are becoming increasingly fuzzy (U1; U2; AN \#3).

\section{Discussion: rethinking legitimacy and authority in global governance}

OECD, UNESCO and WB show growing awareness for the importance of scientific research in the global governance of education as the key sector in the global knowledge society. They increasingly favour exploration instead of exploitation (March 1991). In times when national planning and global governance have been vastly rationalised and scientised (Drori et al. 2003), IOs discover a new role as providers of data, evidence and related policy recommendations. Previous quantitative research has shown their growing scientific output in education (Zapp 2017), yet little was known as to why and how such scientisation at the IO level occurs.

Although the motives of the 'research turn' also include individuals' career planning and the general cohort effect of an increasingly scientifically-trained and developmentspecialised workforce, the ultimate reason for the increase in research capacity is that evidence has become the prime source of authority in governance. IOs, here, increase their socio-political acceptability as a key component of legitimacy by expanding their agenda to include a new mission as scientific 'clearing houses'. It is not surprising that IOs have taken up this role so quickly as they can rely on already highly qualified personnel. The increase in the number of specialised schools of development studies, the related professionalisation of such a global workforce (Chabbott 2003) and the already-existing training infrastructure within IOs (Zapp 2017a) have strongly aided this move.

A new paradigm of evidence is emerging that contrasts with the older, simpler world of 'bricks and mortar type of investments' (W4) and simple increases of enrolment and teacher labour force. This phase has been called a structural expansion phase in previous research (Zapp 2018). New priorities, i.e. more quality in learning and teaching to improve performance (assessment), but also issues of well-being and social skills (neuroscience, psychology) require far more complex approaches for which IOs have put themselves in an agenda-setting position by building up research capacity which (re) gains them legitimacy

Building on the conceptual understanding of legitimacy as composed of socio-political acceptability, reputation and status, findings suggest that these components are not only interrelated but also reinforcing each other (Edwards et al. 2018). Those organisations 
able to increase their acceptability by adjusting their agenda to stakeholders' demands, i.e. providing more research evidence for policymaking, also find it easier to improve their reputation and status and vice versa. Reputation can become in these cases a function of the quality of scientific research conducted. The ambition to remain a leading player in particular research field by continuously exploring new research questions can, then be understood as the attempt to attain greater status vis-à-vis other IOs in the same field.

Such status competition is exacerbated by the fact that the education field is not levelled. As seen with the WB, for example, the most resourceful of the three organisations analysed: a department dedicated specifically to research and a vast array of external experts puts the WB at the pole position in research production. Resources also facilitate wide visibility. The WB uses every possible outlet for diffusing its knowledge including everything from their own scientific journals, conferences and workshops to films and podcasts, whereas the OECD can 'only' count on its limited array of targeted publications. UNESCO, notoriously underfunded, has little original research and field work to offer but sees its job as a synthesiser of existing research and is more limited in transferring evidence. Yet even this arguably limited role has helped UNESCO to survive in its ongoing crisis (Edwards et al. 2018). Here, the legitimacy-granting quality of science is most visible.

However important resources are, they are not the decisive factor in gaining legitimacy. Instead, quality, originality and usability of research seem to matter far more. OECD's PISA project, for example, started relatively small in the late 1990s, yet was considered highly innovative by large parts of the quantitative educational scholarly community (Zapp and Powell 2016). It has, since then, expanded considerably and the OECD has turned into a major player in the research-based governance field. Its buildup reputation now helps it to attract important experts in relevant research fields, which, in turn, allows to adapt more quickly to a new research agenda (O2) showing the recursive relationship between reputation and acceptability/adjustability in legitimacybuilding.

Despite frequent collaboration and common goals, these IOs also use the authority of science against each other to increase their status in a competitive marketplace of educational ideology, expertise and advice, which brings us to two final points about the dominance of particular methodological paradigms and the potential misuse of evidence.

Much recent scholarship has criticised the dominance of a 'medicalised', i.e. applied or economic type of educational research (Tröhler 2015; see Meyer and Benavot 2013 for reviews). Such a quantification has seen considerable momentum through the evidencebased policy-making agenda and is further fanned by the IOs analysed here as all of these subscribe to indicator-based reporting, measurable learning metrics and impact models, most clearly at the OECD and the WB where the economics of education tradition is strongest. At the same time, WB interviewees, although being hired for their quantitative skills, caution against 'putting quantitative approaches and assessments like PISA, PIRLS, TIMSS, and STEP or PIAAC on the pedestal' and despite being 'by its nature, more inclined towards the quantitative side, the Bank is also learning that randomised control trials are not really the gold standard in research and that mixed methods approaches can be far informative' (W3). Further, OECD interviewees hold that it is 'naïve to think that 
the OECD thinks that every kind of educational output is measurable' (O2) and, similarly, UNESCO researchers 'do not believe that the only way forward is to do randomised experiments of some policy question' (U3). Thus, while the quantitative kind of educational research and the economic discipline seem to be increasingly questioned as the dominant paradigm by the interviewed researchers, future research would need to investigate to what degree the objections against monodisciplinary and exclusively numbersbased research are actually translated into a more balanced research agenda at IOs.

Finally, evidence-based policy and practice, sometimes described as the scientisation of politics (Normand 2016), also harbours the risk of the politicisation of science (Dethier 2007; Klees and Edwards 2014; Rao and Woolcock 2007). Policymakers borrow the authority of scientific research to bolster political action and, conversely, IO staff at have found in research the opportunity to refill drained funding lines. In order to increase their own legitimacy and leverage in global governance, but also to win internal funding battles, IOs and particular units within them make use of their expertise, now proven through high academic output and specific evidence. Thus, stressing the role of research does not imply IOs have become depoliticised spaces (Petiteville 2017) and normative underpinnings underlying much educational research at these three organisations as stressed by multiple interviewees (U1; U2; AN \#3) continue to influence and even determine the results.

At the same time, all researchers are aware of what is at stake when the impartiality of science is jettisoned in political and ideological debates. They all made clear that their comparative advantage was exactly their impartial and partly autonomous status. The WB DEC and global practice team is proud of their long-standing autonomy within the WB (W4, W2). UNESCO's GEMR team emphasises that the essential ingredient of their success is the very fact that its funding is not subject to the volatility of the overall UNESCO budget, which gives it more autonomy vis-à-vis member countries. Finally, OECD's CERI is an example for a long struggle for independence since the early period of educational work at OECD (Bürgi 2016). Ironically, OECD work, while being strongly country-driven, has been shown to have the most controversial impacts in member countries (Zapp, Marques, and Powell 2018). Although science and evidence might not replace politics $(\mathrm{O} 2)$, it certainly seems to contribute to keep it at bay.

\section{Conclusion and outlook: the impact of science in global governance}

Based on expert interviews and archival work, this work has investigated the growing importance of scientific research at the three most important intergovernmental organisations active in global education governance, the OECD, UNESCO and WB. Findings support the crucial importance of scientific knowledge in securing legitimacy in a growing policy field. This knowledge has been described as original and innovative as well as objective and policy relevant, i.e. useful and applicable.

In an increasingly crowded and knowledge-intensive global education field, IOs have understood that volume and innovation in the production of policy-relevant educational knowledge as well as the effective dissemination and transfer of that knowledge not only warrants a competitive advantage in the intra- and interorganisational allocation of resources, it has also come to determine the legitimacy, and, some might argue for the case of UNESCO, even survival of IOs in global education governance. 
As IOs are situated in a competitive field where multiple organisations participate and contribute their research knowledge, originality and quality in scientific research also becomes a crucial element in reputation-building and status battles among IOs.

As national and international educational reporting and monitoring systems expand, IOs' capacity and agenda to produce and transfer research knowledge is very likely to expand and with it, their influence on national policymaking. Important avenues for further investigation will include systematic inquiries into the official rhetoric of the role of science for IO work through an analysis of policy documents. The study of financial and human resources dedicated to research at IOs over time will also help to better document IOs' transformation into scientific knowledge hubs. Similarly, while much research has investigated the impact of IO work on national policies, future contributions may reverse the analysis and study IO responses to country demands. While such a focus on knowledge does not imply that other governance mechanisms such as funding and regulation or power politics will lose relevance, a more thorough reconceptualisation of IOs as knowledge actors in global education governance is a task from which scholars of international organisations and comparative education might benefit in explaining educational change worldwide.

\section{Notes}

1. One interviewee had recently retired.

2. OECD and UNESCO did not grant access to their archives upon request.

\section{Acknowledgments}

I am highly indebted to David Baker, Annie Chen, Marcelo Marques, Deena Magnall and Justin Powell.

\section{Disclosure statement}

No potential conflict of interest was reported by the author.

\section{Funding}

Research was supported by a German Academic Exchange Service grant at the American Institute of Contemporary German Studies at Johns Hopkins University Washington (fall/winter 2017).

\section{References}

Barnett, M. N., and M. Finnemore. 2004. Rules for the World: International Organisations in Global Politics. Cornell University Press.

Biesta, G. 2009. "Good Education in an Age of Measurement: On the Need to Reconnect with the Question of Purpose in Education." Educational Assessment, Evaluation and Accountability 21 (1): 33-46. doi:10.1007/s11092-008-9064-9.

Broad, R. 2007. “"knowledge Management': A Case Study of the World Bank's Research Department.” Development in Practice 17 (4-5): 700-708. doi:10.1080/09614520701470094. 
Bryant, A., and K. Charmaz. 2007. "Grounded Theory Research: Methods and Practices." In The Sage Handbook of Grounded Theory, edited by ibid., 1-28. Thousand Oaks, CA: Sage.

Bürgi, R. 2016. “The Free World and the Cult of Expertise. The Rise of OECD's Educationalizing Technocracy." International Journal for the Historiography of Education 6 (2): 159-175.

Chabbott, C. 2003. Constructing Educational Development: International Organisations and Education for All. New York: Routledge Falmer.

Corbin, J., and A. Strauss. 2008. Basics of Qualitative Research. 3rd ed. Thousand Oaks: Sage.

Dethier, J. J. 2007. "Producing Knowledge for Development: Research at the World Bank." Global Governance: A Review of Multilateralism and International Organisations 13 (4): 469-478. doi:10.1163/19426720-01304002.

DiMaggio, P. J., and W. W. Powell. 1983. “The Iron Cage Revisited: Institutional Isomorphism and Collective Rationality in Organisational Fields.” American Sociological Review 48 (2): 147. doi: $10.2307 / 2095101$.

Drori, G. S., J. W. Meyer, F. O. Ramirez, and E. Schofer. 2003. Science in the Modern World Polity: Institutionalization and Globalization. Stanford: Stanford University Press.

Edwards, D. B., T. Okitsu, R. D. Costa, and Y. Kitamura. 2018. "Organisational Legitimacy in the Global Education Policy Field: Learning from UNESCO and the Global Monitoring Report." Comparative Education Review 62 (1): 31-63. doi:10.1086/695440.

Ellis, D. C. 2010. "The Organisational Turn in International Organisation Theory." Journal of International Organisation Studies 1 (1): 11-28.

Gorur, R. 2016. "Seeing like PISA: A Cautionary Tale about the Performativity of International Assessments." European Educational Research Journal 15 (5): 598-616. doi:10.1177/ 1474904116658299.

Jakobi, A. 2009. International Organizations and Lifelong Learning. Basingstoke: Palgrave Macmillan.

Jones, P. W. 2007. World Bank Financing of Education: Lending, Learning and Development. Milton Park: Routledge, Taylor \& Francis Group.

Kallo, J. 2006. "Soft Governance and Hard Values: A Review of OECD Operational Processes within Educational Policy and Relations with Member States." In Supranational Regimes and National Education Policies - Encountering Challenge, edited by J. Kallo and R. Rinne, 261-352. Turku: Finnish Educational Research Association.

Klees, S., and D. B. Edwards. 2014. "Knowledge Production and Technologies of Governance." In Governing Knowledge, edited by T. Fenwick, E. Mangez, and J. Ozga, 31-43. London: Routledge.

March, J. G. 1991. "Exploration and Exploitation in Organisational Learning." Organization Science 2 (1): 71-87. doi:10.1287/orsc.2.1.71.

Meyer, H. D., and A. Benavot. 2013. PISA, Power, and Policy: The Emergence of Global Educational Governance. Oxford: Symposium Books.

Moutsios, S. 2009. "International Organisations and Transnational Education Policy." Compare: A Journal of Comparative and International Education 39 (4): 469-481. doi:10.1080/ 03057920802156500 .

Mundy, K. 2007. "Educational Multilateralism - Origins and Indications for Global Governance." In New Arenas of Education Governance. The Impact of International Organisations and Markets on Educational Policy Making, edited by K. Martens, A. Rusconi, and K. Leuze, 19-40. Basingstoke: Palgrave Macmillan.

Niemann, D., and K. Martens. 2018. "Soft Governance by Hard Fact? the OECD as a Knowledge Broker in Education Policy." Global Social Policy 18 (3): 267-283. doi:10.1177/ 1468018118794076.

Normand. 2016. The Changing Epistemic Governance of European Education. The Fabrication of the Homo Academicus Europeanus? Dordrecht: Springer International Publishing.

Nye, J. S. 1990. “Soft Power." Foreign Policy, (80): 153-171. doi:10.2307/1148580.

Oancea, A. 2007. "From Procrustes to Proteus: Trends and Practices in the Assessment of Education Research.” International Journal of Research \& Method in Education 30 (3): 243-269. doi:10.1080/17437270701614766. 
Parreira do Amaral, M. 2010. "Regime Theory and Educational Governance: The Emergence of an International Education Regime.” In International Educational Governance, edited by S. K. Amos, 59-80. Oxford: Emerald.

Pavone, V. 2007. "From Intergovernmental to Global: UNESCO’s Response to Globalization.” The Review of International Organisations 2 (1): 77-95. doi:10.1007/s11558-006-9000-z.

Petiteville, F. 2017. "International Organisations beyond Depoliticized Governance." Globalizations 15 (3): 301-313. doi:10.1080/14747731.2017.1370850.

Rao, V., and M. Woolcock. 2007. "The Disciplinary Monopoly in Development Research at the World Bank." Global Governance: A Review of Multilateralism and International Organisations 13 (4): 479-484. doi:10.1163/19426720-01304003.

Scherrer, C. 2007. "GATS: Commodifying Education via Trade Treaties." In New Arenas of Education Governance: The Impact of International Organisations and Markets on Educational Policy Making, edited by S. Leibfried, A. Rusconi, K. Leuze, and K. Martens, 117-135. London: Palgrave.

Scott, W. R. 2013. Institutions and Organisations: Ideas, Interests and Identities. Sage Publications. Steiner-Khamsi, G. 2009. "International Knowledge Banks in Education." In State and Market in a Globalized World, edited by D. Junker, W. Mausbach, and M. Thunert, 251-270. Heidelberg: Winter.

Suchman, M. C. 1995. "Managing Legitimacy: Strategic and Institutional Approaches." The Academy of Management Review 20 (3): 571-610. doi:10.2307/258788.

Tallberg, J., and M. Zürn. 2019. “The Legitimacy and Legitimation of International Organisations: Introduction and Framework." Review of International Organisations. (online first edition). doi:10.1007/s11558-018-9330-7.

Tröhler, D. 2015. "The Medicalization of Current Educational Research and Its Effects on Education Policy and School Reforms." Discourse: Studies in the Cultural Politics of Education 36 (5): 749-764. doi:10.1080/01596306.2014.942957.

Wejnert, B. 2002. "Integrating Models of Diffusion of Innovations: A Conceptual Framework." Annual Review of Sociology 28 (1): 297-326. doi:10.1146/annurev.soc.28.110601.141051.

Wiseman, A. W., M. F. Astiz, and D. P. Baker. 2014. "Comparative Education Research Framed by Neo-institutional Theory: A Review of Diverse Approaches and Conflicting Assumptions." Compare: A Journal of Comparative and International Education 44 (5): 688-709. doi:10.1080/03057925.2013.800783.

Zapp, M. 2017. "The Scientization of the World Polity. International Organizations and the Production of Scientific Knowledge, 1950-2015.” International Sociology. doi:10.1177/ 0268580917742003.

Zapp, M. 2017a. "The World Bank and Education: Governing (Through) Knowledge." International Journal of Educational Development 53: 1-11. doi:10.1016/j.ijedudev.2016.11.007.

Zapp, M. 2017b. "Higher Education Expansion and the Growth of Science: The Institutionalization of Higher Education Systems in Seven Countries, 1945-2015." In The Century of Science: The Global Triumph of the Research University, edited by J. J. W. Powell, D. P. Baker, and F. Fernandez, 37-53. Bingley, UK: Emerald.

Zapp, M. 2018. "Beyond Large-Scale Achievement Testing - The Psychological Turn in International Organizations' Work on Educational Assessment.” In Cross-nationally Comparative, Evidence-based Educational Policymaking and Reform, edited by A. Wiseman and P. M. Davidson. Bingley, UK.

Zapp, M. 2019. "Empowerment for Individual Agency: An Analysis of International Organizations' Curriculum Recommendations." Globalisation, Societies and Education 17: 231-260. doi:10.1080/14767724.2019.1577717.

Zapp, M., and C. Dahmen. 2017. "The Diffusion of Educational Ideas-An Event History Analysis of Lifelong Learning, 1990-2015.” Comparative Education Review 61 (3): 492-518. doi:10.1086/ 692607.

Zapp, M., and J. J. W. Powell. 2016. "How to Construct an Organizational Field: Empirical Educational Research in Germany, 1995-2015.” European Educational Research Journal 15 (5): 537-557. doi:10.1177/1474904116641422. 
Zapp, M., M. Marques, and J. J. W. Powell. 2018. European Educational Research (Re-)constructed: Institutional Change in Germany, the United Kingdom, Norway and the European Union. Oxford Studies in Comparative Education. Oxford: Symposium Books.

Zürn, M. 2018. A Theory of Global Governance: Authority, Legitimacy, and Contestation. Oxford: Oxford University Press. 